Chirurgia (2017) 112: 217-228

No. 3, May - June

Copyright $\odot$ Celsius

http://dx.doi.org/10.21614/chirurgia.112.3.217

\title{
Living Donor Liver Transplantation
}

\author{
Birkan Bozkurt, Murat Dayangac, Yaman Tokat \\ Istanbul Bilim University Florence Nightingale Hospital Liver Transplantation Unit, Istanbul, Turkey
}

Corresponding author:

Associate Professor Birkan Bozkurt

Sisli Florence Nightingale Hospital

Liver Transplantation Center

Abide-iHurriyet cad. No:164 Sisli

34381 Istanbul, Turkey

E-mail: birkan.bozkurt@gmail.com

\section{Rezumat}

Transplantul hepatic de la donator viu

La 50 de ani de la primul transplant hepatic, aceasta a devenit una din cele mai recunoscute ramuri ale chirurgiei. În această perioadă, transplantul hepatic combinat cu tehnicile chirurgicale, selecția pacienților, evoluția anesteziei şi a îngrijirii postoperatorii şi creșterea experientei, a devenit opțiunea cea mai eficientă de tratament a afecțiunilor hepatice acute şi cronice. În plus, restricția la nivel mondial de folosire a organelor şi rata mare a mortalității pacienților aflați pe lista de aşteptare pentru transplantul de organe, a dus la acceptarea folosirii donatorilor vii, pentru a extinde baza de donatori. Această lucrare explică indicațiile transplantului hepatic de la donatori vii, tehnica chirurgicală folosită, complicațiile acestei proceduri şi tratamentul medical utilizat.

Cuvinte cheie: transplantul hepatic, donatori vii, transplant de la donatori vii

\section{Abstract}

In 50 years after the first liver transplantation, the medical world has witnessed the liver transplantation to become one of the widely recognized and leading branches of surgery. In this period, liver transplantation combined with surgical technique, patient selection, advancements in anesthesia and postoperative care and increased experience has become the most effective treatment option in treatment of several acute and chronic liver diseases. Yet, the worldwide organ restriction and associated 
high mortality rates in organ transplantation waiting list has compelled referring to living donors in order to expand the donor pool. This paper explains liver transplantation indications from living donors, the surgical technique involved, the complications of the procedure and the medical treatments used.

Key words: liver transplantation, living donors, living transplantation

\section{Introduction}

Liver transplantation which is recognized today as the golden standard in treatment of endstage liver failure is being increasingly conducted with the advances in surgical techniques and perioperative methods. Liver transplantation which was first conducted by Starzl in 1963 from a cadaver donor then rapidly spread to the whole world, and the living donor transplantation was first conducted in 1989 from an adult to a child. Left lobe liver transplantation from an adult to another adult in 1993 was followed by right lobe liver transplantation in 1996 (1-4). The failure of the policy for organ donation in the face of the spread of practicality of transplantation caused a rapid increase in the number of waiting patients but the number of cadavers was insufficient, which led to emergence of new approaches in transplantation from cadavers. In order to overcome this problem, liver transplantation from living donors is the most novel and promising method for the patients awaiting organ. The objective of this paper is to summarize, in parallel with the literature, the indications of liver transplantation from living donors, the perioperative preparation, the surgical technique involved and the complications of the procedure.

\section{Background and Development of Liver Transplantation}

The first successful liver transplantation from a living donor was achieved in 1989 from an adult to a child by Strong et al. in Australia (2). In 1990 s, unlike western societies, transplantation was often conducted from living donors in Asian communities, in particular Japan, due to the cultural values not allowing transplantation from a cadaver, but still transplantation from cadaver remained at quite low values as 5 in a million. In western societies on the other hand, transplantation from cadaver had a relatively higher rate of $10-35$ in a million thanks to nonexistence of a restriction in this matter in these societies (5). In fact, being desperate in finding sufficient cadavers the world tried to develop new approaches in finding organ, and left lobe transplantation from an adult living donor to another adult was first achieved by Makuuchi et al. in 1993 in Japan and it was successful (3). Efforts were put to improve the surgical technique in order to reduce the complications of this major operation and make it more practical, and Fan et al. conducted the first right lobe transplantation along with the medial hepatic vein in 1996 (4). The first successful right lobe transplantation was conducted by Wachs et al. in 1997 without using medial hepatic vein as a result of improvement of the operation to reduce complications (6). These efforts resulted in a rapid increase in the number of transplantations in Asia, Europe, North and South America after 1997.

\section{Indications of Transplantation}

When the life expectancy of the transplantation candidate without liver transplantation goes below the survival expectancy of liver transplantation, the transplantation has to be planned. The necessity of liver transplantation usually arises in case of refractory acid, subacute bacterial peritonitis, chronic encephalopathy, recurring variceal hemorrhage, hepatorenal syndrome and hepatopulmonary syndrome as major complications accompanying the failure of liver synthetic functions and the significant 
decrease of life quality and expectancy in connection with the liver disease.

The most prevalent liver transplantation indications are viral hepatitis, and cirrhosis associated with alcohol in adults, and biliary atresia in pediatric group (Table 1). While there is overall a good life expectancy in compensated cirrhosis (approximately 90\% in 5 years), 5-year survival rate in the patients developing decompensation findings is below $50 \%$. Patients with chronic liver disease must be closely monitored until the period when

Table 1. Liver transplantation indications

\begin{tabular}{|c|c|}
\hline \multirow[t]{5}{*}{ Chronic parenchyma diseases } & Chronic hepatitis B \\
\hline & Chronic hepatitis C \\
\hline & $\begin{array}{l}\text { Liver cirrhosis associated with } \\
\text { alcohol }\end{array}$ \\
\hline & Autoimmune hepatitis \\
\hline & Cryptogenic cirrhosis \\
\hline \multirow[t]{6}{*}{ Cholestatic liver diseases } & Primary biliary cirrhosis \\
\hline & Secondary biliary cirrhosis \\
\hline & Primary sclerosing cholangitis \\
\hline & Biliary atresia \\
\hline & Alagille syndrome \\
\hline & Familial intrahepaticcholestasis \\
\hline \multirow[t]{6}{*}{$\begin{array}{l}\text { Metabolic diseases } \\
\text { that lead to cirrhosis }\end{array}$} & Hemochromatosis \\
\hline & Alpha 1 antitrypsin deficiency \\
\hline & Wilson disease \\
\hline & $\begin{array}{l}\text { Non-alcoholic steatohepatitis } \\
\text { (NASH) }\end{array}$ \\
\hline & Tyrosinemia \\
\hline & Glycogen storage diseases \\
\hline \multirow[t]{3}{*}{$\begin{array}{l}\text { Metabolic diseases leading } \\
\text { to non-hepatic disorders }\end{array}$} & Amyloidosis \\
\hline & Hyperoxaluria \\
\hline & Urea cycle disorders \\
\hline \multirow[t]{2}{*}{ Acute fulminant liver failure } & Viral hepatitis \\
\hline & Toxichepatitis \\
\hline \multirow[t]{5}{*}{ Malign diseases } & Hepatocellularcarcinoma \\
\hline & Hemangioendothelioma \\
\hline & Hepatoblastoma \\
\hline & Cholangiocarcinoma \\
\hline & Metastatic neuroendocrine tumors \\
\hline \multirow[t]{3}{*}{ Other diseases } & Polycystic liver disease \\
\hline & Budd-ChiariSyndrome \\
\hline & Alveolar echinococcus \\
\hline
\end{tabular}

they would need liver transplantation and must be assessed with regards to clinical decompensation findings, and monitored through radiological imaging and alpha-fetoprotein levels with regards to hepatocellular carcinoma (HCC) development.

Acute liver failure in which liver transplantation holds a significant position in treatment comprises approximately $10 \%$ of the liver transplantation indications. Acute liver failure might occur as fulminant liver failure, as well as developing on the basis of chronic liver diseases such as Wilson's disease, chronic hepatitis B and autoimmune hepatitis. Fulminant liver failure is the development of acute liver failure and hepatic encephalopathy within 2-8 weeks from the start of the disease in the patient who has not had liver disease before. The major causes are acetaminophen intoxication, idiosyncratic drug reactions, hepatitis A and B infections, Budd-Chiari syndrome and fungus intoxication.

Uncontrollable pulmonary hypertension, sepsis, severe cardiopulmonary failure, extrahepatic malign disease, active substance addiction, irreversible brain damage and medical incompatibility of the patient can be counted among the contraindications of liver transplantation. Today, portal vein thrombosis (PVT), HIV positivity, previous abdominal surgery and cholangiocellular carcinoma are not counted as definite contraindications for liver transplantation (7).

\section{Assessment before Living Donor Liver Transplantation}

\section{Perioperative Assessment of Recipient in Liver Transplantation}

Ascites development, esophageal variceal hemorrhage, spontaneous bacterial peritonitis and hepatorenal syndrome, which are major complications of end-stage liver disease, significantly affect the prognosis. Other methods used in determining prognosis are Child-TurcottePugh (CTP) and Model for End-Stage Liver Disease (MELD) scoring systems. CTP classification, which is done using the degree of encephalopathy and ascites, and serum 
bilirubin and albumin levels and prothrombin time, was designed to identify the risk of shunt surgery in cirrhotic patients and later gained popularity in determining the prognosis of chronic liver disease (8). More than one third of the patients with CTP score above 10 (Child C) are lost in a year (9). On the other hand, 5-year survival chance of those with CTP score 7-9 (Child B) is $80 \%$, and those with CTP score 5-6 (Child A) has a survival chance more than 5 years by $90 \%$ (10). MELD, which has now replaced CTP scoring, was essentially developed in order to determine short-term prognosis of the patients who went through transjagular intrahepatic portosistemic shunt (TIPS). The scoring which is conducted according to bilirubin, INR and creatinine values was found to be the best marker of 3-month survival among the patients who were provided TIPS (11). Subsequent studies showed that MELD model modified for liver transplantation defined the mortality both in waiting list and posttransplantation period (12). Due to being a mathematical computation predicated on laboratory values, MELD offers a patient selection system based on objective criteria. This scoring system is significant for only showing mortality since it is based on consent as the transplantation is conducted from a relative in case of live transplantation.

Another step in considering liver transplantation is to determine whether the patient is a suitable candidate for the transplantation. The transplantation candidate is assessed in a multidisciplinary manner investigating whether there is an accompanying condition or graft or a condition that would negatively affect survival that prevents liver transplantation and whether the patient could comply with the complex medication regimes and follow-up protocols following the transplantation. HCC screening is a significant part of this assessment.

Yet, the successful outcomes defined by Mazzaferro et al. in a single tumor case or 3 or less tumors with a size of $2-5 \mathrm{~cm}$ or not larger than $3 \mathrm{~cm}$ with no extrahepatic metastasis helped to redefine the patient selection criteria (13). The 5-year survival rates of liver transplantation for HCC patients with said tumor characteristics, called Milan criteria, became equal to the rates of the transplantations conducted for reasons outside HTCC (14).

\section{Donor Selection in Liver Transplantation with Living Donor}

It was demonstrated that with the living donor liver transplantation, the recipient survival increased, and the patient deaths on the waiting list decreased as well $(15,16)$. The biggest ethical problem with living donor liver transplantation is putting a completely healthy individual at risk. Although it can be considered that this is beneficial since donors are saving the life of someone they love, the multicenter studies show that complications develop in $38 \%$ of the living donors and the donor mortality is $0.2 \%$ on average $(0.3-0.5 \%$ in right lobe donors) $(17,18)$.

Despite the fact that living donors are usually selected among the family members or close relatives, some centers also accept unrelated donors. Although there is no clear definition for an ideal living liver donor, usually the donors aged 20-50 having the same blood group with the recipient with body mass index lower than 30 and with no hepatosteatosis and accompanying health issue and with calculated remnant liver volume higher than $35 \%$ of the liver are preferred. Yet, most transplant centers accept the donors outside these limits (19).

Donor preparation is intended for identification of donor hepatosteatosis risks as much as assessing donor's compatibility with the recipient, and follows a flowchart composed of a few successive steps (Fig. 1). The first stage in donor selection is to advise the donor candidate about the risks of surgery and life expectancy of the recipient. It must be ensured that each point is perfectly understood, and the donor must be granted sufficient time to think throughout the assessment. A full psychosocial assessment is necessary in order to ensure that the decision of the donor is totally upon consent and not based on any family pressure.

Medical assessment of the donor includes a detailed medical history and physical examination along with the biochemical parameters. It is 


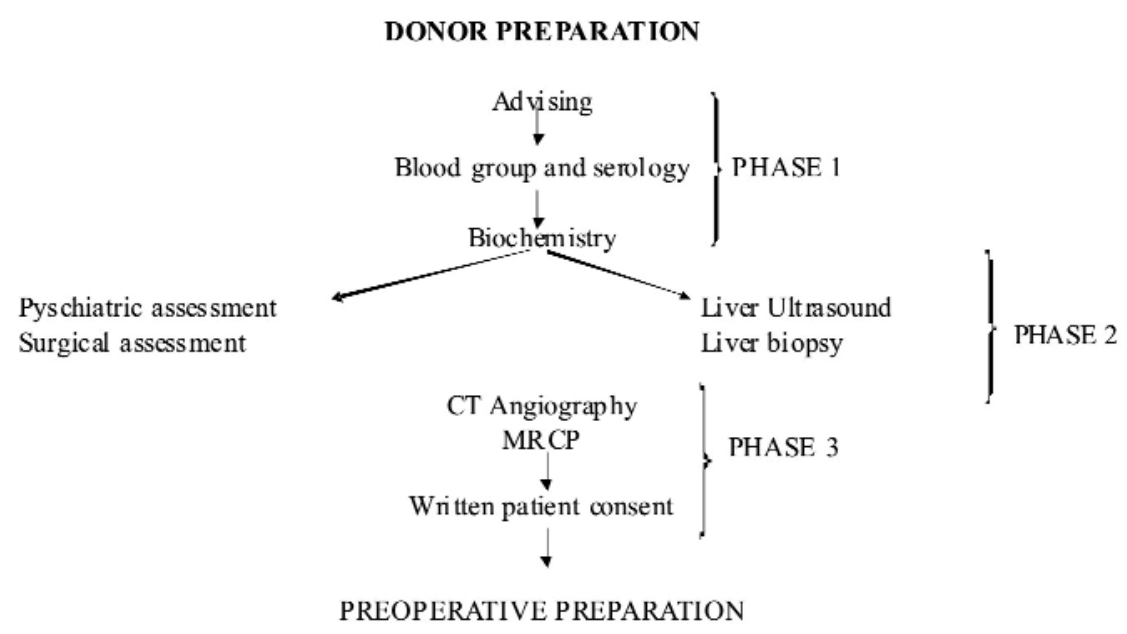

Figure 1. Donor preparation algorithm for living donor liver transplantation

necessary to review liver and kidney functions, hematological parameters and hepatitis serology. Among these, lung graph and liver ultrasound are conducted as a part of radiological examination. Ultrasound is particularly important for assessing major hepatic lesions and hepatosteatosis. The donor candidates with severe hepatosteatosis are disqualified in this stage, and the decision about those with moderate steatosis is given at the end of the liver biopsy. Although there are centers conducting routine liver biopsy, there is a tendency today to conduct an elective biopsy considering parameters such as hepatosteatosis, autoimmune liver disease in the family, hepatitis B, core antibody positivity and the high body mass index. Advanced cardiologic and pulmonary tests are conducted electively.

The third stage of donor selection is predicated upon radiological examinations. Computer tomography (CT) or magnetic resonance imaging (MRI) is preferred to assess vascular anatomy and volume of liver, and magnetic resonance cholangiography (MRC) is preferred to assess the anatomy of bile ducts. Preoperative liver volumetry in living donor liver transplantation is one of the most significant steps of donor preparation. Although there is software custom designed for liver volumetry, most centers use CT as a standard method. Calculating liver volume of the donor preoperatively is of great importance particularly in living donor liver transplantation for avoiding negative circumstances to be caused by insufficient graft volume in the recipient, and for leaving sufficient remnant volume in the donor as well. Small-forsize syndrome is a clinical condition resulting from the use of a liver with insufficient volume for the recipient and accompanied by prolonged cholestasis, coagulopathy and persistent ascites (20). In order to avoid this, the necessary minimum liver volume is calculated in reference to the liver graft's ratio to recipient's bodyweight or its ratio to standard liver volume measured according to the recipient's body surface area. There is a general belief that the ratio of graft weight to bodyweight in case of split living donor liver transplantation must be $0,8 \%$, and its ratio to liver volume must be above $30 \%$ (21). The ratio of right lobe, which is most frequently used in living donor liver transplantation, to the whole liver volume might range between $24 \%$ and 50\% (22). Remnant liver volume has to be above $30 \%$ for the safety of the donor (23).

\section{Living Donor Liver Transplantation Technique}

\section{Living Donor Operation Technique}

As a standard, $\mathrm{j}$-shaped incision and Mercedes incision, when required, are used. After the 
right triangular and coronary ligaments are separated in right hepatectomy of the donor, hepatic vein configuration, and particularly segment IVb, segment V, segment VIII drainage veins and accessory inferior RHV presence and vein diameters are assessed through intraoperative ultrasound, and the data are then compared to preoperative CT angiography findings. Cholecystectomy is then conducted by separating cystic artery and cystic duct. Hilus dissection is conducted to remain in the right side of the main bile duct, and then right hepatic artery (RHA) and right portal vein (RPV) are suspended. Dissection in donors having middle hepatic artery (MHA) stemming from RHA is conducted to preserve MHA in order not to disturb the feeding of segment IV in remnant liver. Intraoperative cholangiography must be conducted in those with insufficient preoperative MRCP findings or with atypical bile anatomy.

Following right lobe mobilization, caudate lobe is separated in front of IVC, and all short hepatic veins and hepatocaval ligament are separated along IVC up to RHV junction. The decision to preserve major ( $>5 \mathrm{~mm}$ ) accessory inferior hepatic veins, which allow the drainage of segments VI and VII found at that point, must be given according to the ischemic test clamping to be conducted. The retrohepatic dissection is then completed, and hepatocaval ligament is separated, and the liver is then fully mobilized to the left. After suspending RHV, RHA and RPV are temporarily clamped and Cantlie line is marked. Parenchyma transection is usually conducted accompanied by bipolar cautery and ultrasonic dissector (CUSA, Cavitron). Pringle maneuver is preferred during donor hepatectomy lest ischemic damage might be inflicted on the graft and remnant liver during transection. Yet, it must not be hesitated to conduct Pringle for donor safety in case of major hemorrhage during parenchyma transection. The crucial factors to reduce bleeding during donor hepatectomy is keeping central venous pressure below $5 \mathrm{~cm} \mathrm{H} 2 \mathrm{O}$ and conducting a careful ultrasonic dissection.

The transection starts on the plane extending from the left side of biliary sac bed to the projection of hepatic canal bifurcation. Upon reaching segment 5 junction, the transection continues, depending on the decision about taking MHV, incising into the left lobe staying on the right of the vein along MHV surface after binding and separating segment $\mathrm{V}$ vein or preserving segment $\mathrm{V}$ and causing MHV to remain on the cross section. It must be borne in mind the transection follows an oblique line along MHV rather than a vertical line. MHV dissection is completed up to vena cava junction preserving segment IVb vein. The use of MHV is still controversial today (24). The controversy focuses on the fact that the right lobe grafts prepared by taking medium hepatic vein is technically a more difficult operation rather than its results in the recipient and that there are concerns about donor safety due to the likelihood of deformation of parenchyma regeneration and venous drainage in paramedian sector of the remnant liver.

After dissecting portahepatis and separating portal vein, the right bile duct or ducts are marked with a marker, and intraoperative cholangiography is conducted. The integrity of the plane between RHA and right bile duct, and the liver tissue around hepatic canal must be preserved in order to preserve the feeding of bile duct.

The synchronous recipient operation has now reached to hepatectomy stage. After confirmation, the bile duct is cut on the line determined and this is followed by systemic heparinization. And RHA and ROV are tied and separated. Finally, RHV and MHV, if any, are clamped and separated and donor right hepatectomy is then completed. After closing hepatic vein stumps, portal vein stump and bile duct, it must be checked whether there is any bile leakage from hepatic canal stump or cross section by injecting methylene blue through the cystic duct, and the integrity of remnant bile ducts must be demonstrated through a new cholangiogram.

After completing the right hepatectomy, the falciform ligament must be fastened to the front abdominal wall to counter the possibility that remnant left lobe might twist hepatic veins by tumbling on the right subphrenic cavity. 
In case of donor's left hepatectomy, the same stages in right hepatectomy are symmetrically followed. Since left lobe graft is to be prepared with MOHL, parenchyma dissection is conducted along right edge of MOHL. If larger graft volume is required, caudate lobe can also be included in left lobe graft.

After weighing removed liver graft, cold perfusion is conducted through portal vein using HTK (Histidine-tryptophan-ketoglutarate) solution (Custodiol $\AA$ ) or UW (University of Wisconsin) (Viaspan $\mathbb{R})$. In the meantime, reconstructions required for hepatic vein, portal vein or bile ducts, and vascular graft interpositions, if required, can be conducted. RHV and MOHL are anastomosed to create a joint orifice if right lobe graft is taken together with MOHL. Vein space must be measured in this reconstruction to be made in triangular shape, and the result must be reported to the recipient's team to plan hepatic vein anastomosis to be conducted on the recipient side.

Since the venous congestion to occur as a result of the failure to provide sufficient venous drainage for liver would cause distortion of regeneration of related liver area, it is important to separately drain segment $\mathrm{V}$ and VIII veins when major accessory hepatic veins and $\mathrm{MHV}$ are not taken for right lobe transplantation (25).

Apart from hepatic veins, the reconstruction of portal vein and hepatic canal, if required, needs to be completed in this stage. Side-to-side reconstruction or Y-graft interposition can be implemented for double portal vein anomaly which is found in less than $10 \%$ of donors (26).

Multiple bile ducts can be found in right lobe grafts with a rate up to $40 \%$ (27). Although these ducts are separately anastomosed both in ductto-duct anastomosis or hepaticojejunostomy techniques, it is possible to create a single orifice through back-table plasty. However, this technique might increase complication possibility due to ischemia in bile ducts. (28).

\section{Recipient Operation}

Recipient hepatectomy is conducted by "piggy back" technique preserving vena cava as the case with cadaveric liver transplantation. However, unlike the hepatectomy conducted for cadaveric graft, hilus dissection starts at "hilar plate" level in order to allow hilar structures to be as lengthy as possible.

In order to prevent excessive traction during liver mobilization, the branches of left hepatic artery (LHA) first and then segment 4 hepatic artery (MHA), if any, are separated approaching from the left. Because hemostasis maneuvers and retrograde bleeding might cause intimal split. After separating hepatic artery branches, right and left hepatic canals distal to bifurcation are separately dissected and disjoined. In the meantime, care must be exercised to preserve the vascular network that feeds the main bile duct. Hepatoduodenal dissection is completed by fully simplifying portal vein. If a temporary portacaval shunt is not planned, it is not necessary to tie right and left portal vein branches separately since main portal vein is usually used in portal vein anastomosis. Afterwards, caudate lobe is removed, and all short hepatic veins and hepatocaval ligament are separated. After suspending right hepatic vein, left lobe and left hepatic vein (LHV) are mobilized up to MHV junction. In the last stage, after confirming that graft liver is ready, the portal vein and hepatic veins are separated and hepatectomy is completed. In order to minimize portal vein pressure, it is preferred to separate portal vein in late stage after removing and preparing donor's liver. Hepatic vein anastomosis must be completed without total IVC clamping as far as possible in order to preserve hemodynamic stabilization and renal functions. Yet, if the recipient is able to tolerate total IVC clamping, such clamping must be preferred instead of partial clamping due to complex venous anatomy in grafts where venous reconstruction is conducted in order to provide suitable venous drainage. After closing the orifices of MHV and LHV for right lobe transplantation, the orifice of $\mathrm{RHV}$ is prepared in order to create a large triangle, and then hepatic vein anastomosis is completed. Accessory hepatic vein anastomoses, if any, are also anastomosed to IVC as end-side. Following completion of hepatic vein anasto- 
mosis, the recipient portal is prepared for the new anastomosis. In patients with portal vein thrombosis, portal clamp is opened in this stage to conduct tromboendovenectomy, and it is ensured that sufficient portal flow is provided. The length of portal vein must be adjusted so that it will not cause a kink when it is brought end to end with graft portal vein. After completing end-to-end portal vein anastomosis, hemostasis is primarily checked by opening hepatic vein clamps. Having ensured hemodynamic stabilization, portal clamps are opened to allow reperfusion. In this stage, the fact that the graft returns to its normal color homogenously without being hard is a leading indicator of sufficient venous drainage and absence of portal hyperperfusion.

Hepatic artery anastomosis must be conducted using microsurgical method with individual monofilament sutures. The selection of artery to be used for anastomosis is done according to placement, diameter compatibility, morphology and flow features. Following artery anastomosis, hepatic and portal vein artery flows must be assessed through Doppler US. This approach particularly allows assessing morphological features of quite small hepatic arteries besides their qualitative and quantitative flow patterns and also solves artery problems intraoperatively (29). Biliary anastomosis is conducted through duct-to-duct technique and individual sutures as far as possible. The condition of vascular anastomoses must be followed through serial Doppler US examination to be conducted postoperatively.

The most frequently preferred method for biliary anastomosis is duct-to-duct method without $\mathrm{t}$-tube through individual sutures (27). Hepaticojejunostomy, the classic technique, is less frequently used in our time due to technical problems such as edema associated with portal clamping on bowel loop which is used for anastomosis, and thickening associated with peritonitis and short mesentery, as well as its being more difficult and time-consuming. However, hepaticojejunostomy is preferred where recipient's bile ducts are not suitable. Besides back-table reconstruction, separate anastomosis is also possible for multiple bile ducts. After completing anastomosis, it must be checked whether there is any bile leakage from anastomosis line and cross section using the methylene blue injected into the cystic canal. It must be ensured that there is no obstruction distal to the main bile duct to be used for ductto-duct anastomosis, and bile anatomy and contrast transition to duodenum must be demonstrated through cystic cholangiography following completion of anastomosis. Bleeding control must be completed before anastomosis since bile anastomosis traction might cause bile leakage, and traction must be avoided when anastomosis is required following hemostasis.

In case of left lobe transplantation, RHV orifice is closed, and MHV and LHV junction is prepared for anastomosis. The purpose at this point is to create a large triangular space. In grafts prepared with caudate lobe, it was demonstrated that anastomosing caudate lobe vein to IVC through back-table plasty or separately is important for caudate lobe regeneration (30). Bile duct reconstruction can be conducted as duct-to-duct or HJ according to the condition of recipient's bile tract.

\section{Transplantation Complications}

Early postoperative course following liver transplantation (LT) might be significantly variable depending on the complications associated with end-stage liver disease (ESLD), the features of the selected liver graft, and major surgical intervention implemented, and accompanying problems of the recipient and adverse effects of the treatment that suppresses immunity. Although technical problems associated with surgery are at the forefront during the early stages, there is a much larger complication spectrum that transplant physicians have to face, and the follow-up of LT must be ideally managed with a multidisciplinary approach (Table 2).

\section{Primary Non-function}

Primary non-function is the most prevalent reason why a technically smooth liver graft is lost during the early period. The clinical 
Table 2. Complications following liver transplantation

\begin{tabular}{ll}
\hline Vascular complications & $\begin{array}{l}\text { Hepatic artery thrombosis, stenosis, } \\
\text { pseudoaneurysm }\end{array}$ \\
& Portal vein stenosis, thrombosis \\
& IVC, hepatic vein thrombosis, stenosis \\
\hline Bile complications & Bile leakage, biloma \\
\hline Other complications & Bile stricture, stones, Oddistenosis \\
\hdashline & Primary non-function \\
\hline & Acuteand chronic rejection \\
\hline & Infections \\
\hline & Disease recurrence (Hepatitis C, \\
Hepatitis B, Autoimmune hepatitis, \\
Primary sclerosing cholangitis, HCC)
\end{tabular}

picture looks like fulminant hepatic failure. Histologically, it is a condition accompanied by hepatocyte necrosis without vascular complication, and coagulopathy, encephalopathy, and rapidly rising serum transaminases and lactate necrosis and progressive multiorgan failure, resulting in replantation or death.

\section{Acute and Chronic Rejection}

The most frequent reason behind function disorder in graft liver in early period following transplantation is acute rejection that is accompanied by rise in transaminases, alkaline phosphatase and bilirubin levels. Acute rejection after liver transplantation appears within the first 6 weeks in half of the patients. Except failure to provide sufficient immunosuppression, it appears in association with conditions such as prolonged ischemia reperfusion damage, young recipient age, old donor age and autoimmune disease. Although it may appear clinically with fever, leukocytosis and right upper quadrant pain, the most reliable diagnosis method is liver biopsy since the patients are often asymptomatic and there is no definitive biochemical test.

Definitive diagnosis includes ischemia reperfusion damage, bile duct obstruction, cholestasis associated with sepsis, vascular ischemia, viral and autoimmune hepatitis and drug toxicity. Damage in bile ducts and portal inflammation accompanied by eosinophile found in liver biopsy are diagnostic. Response to high doses of steroid treatment is available and liver function tests rapidly come to normal levels.

Lifelong clinical monitoring and sufficient immunosuppressive treatment following liver transplantation are of great importance in order to prevent chronic rejection often resulting in cirrhosis and graft loss. Chronic rejection appearing $2-3 \%$ of patients occurs most of the time between $6^{\text {th }}$ week and $6^{\text {th }}$ month after the transplantation. Jaundice appears in the final stage following cholestatic enzyme increase clinically developing over weeks. The histological diagnostic criteria, as defined by Banff, are cytoplasmic eosinophilia, lymphocytic portal inflammation, obliterative arteriopathy and bile duct loss that affect more than half of the portal areas (31). Around 20\% of liver retransplantations cannot be conducted due to chronic rejection (32).

\section{Infections}

Despite effective antibiotic prophylaxis practices, infection continues to be a significant cause of morbidity and mortality following liver transplantation. It is reported that $80 \%$ of the recipients develop infection at least once in the first year following the transplantation (33). Bacterial pathogens, being the most frequent factors, cause infection development particularly in surgical site, abdominal cavity, blood, urinary tract and respiratory tract.

\section{Vascular Complications}

Vascular complication that develops following liver transplantation despite advancements in surgical techniques and especially microvascular reconstruction techniques is still an important source of morbidity and mortality. Most prevalent complications following liver transplantation are thrombosis, stenosis and pseudoaneurysm, which usually appear within 3 months following the transplantation. The clinical picture shows that radiology plays a significant role in both diagnosis and treatment of vascular complications due to the challenges in distinguishing them from other posttransplant complications (bile complications, 
acute rejection, infections).

Hepatic artery thrombosis (HAT) is the most prevalent vascular complication following liver transplant, and reported with rates ranging between $2-20 \%$ and $9-15 \%$ in adults and pediatric group, respectively (34). HAT is a leading complication resulting in graft losses (35). Early HAT causes severe damage in hepatocytes and epithelium cells of bile duct, and might result in fulminant necrosis, bile leakage, cholangitis and sepsis. Ischemic damage in bile ducts, in particular, might lead to secondary bile strictures (ischemic cholangiopathy), intrahepatic biloma and abscess development. Approximately one third of those developing HAT exhibits a clinical course resulting in graft and patient loss if accompanied by parenchyma necrosis and if not remedied rapidly, while one third of the patients exhibits an asymptomatic course. The other one-third group develops cholangiopathy associated with ischemia in bile ducts rather than parenchyma necrosis (36). Technical reasons (intimal dissection, back-table reconstruction, multiple anastomoses, prolonged ischemia time) as well as reasons outside surgery such as immunological factors, coagulation disorders, $\mathrm{ABO}$ blood incompatibility and infections also play a role in HAT development $(37,38)$.

Portal vein thrombosis (PVT) is a rare complication and reported only by $1-3 \%$ (39). PVT is the circumstance usually involving problems associated with surgical technique, and leaving portal vein longer and leakages associated with hypercoagulopathies and previous portosystemic shunts. Acute portal vein thrombosis results in graft loss and death if not remedied rapidly in the early period, while portal vein thrombosis developing in later periods are better compensated and exhibits a progressive course accompanied by portal hypertension development.

\section{Bile Duct Complications}

Living donor liver transplantation is especially a risk factor in and of itself in terms of bile complications. Bile duct complications reach to a rate of $60 \%$ in living donor liver transplantation
(27). Bile complications occur in most patients within the first 6 months following liver transplantation. Thanks to the advancements in diagnosis and treatment, bile complications rarely result in graft and patient loss in our time, but continue to be a significant source of morbidity.

Bile anastomosis in liver transplantation is conducted through choledocholedochostomy (CC) or hepaticojejunostomy (HJ) technique. Today, CC has replaced HJ thanks to the advantages it provides. These advantages are that it prevents ascending cholangitis risk and infiltration of intestinal contents into abdomen in case of bile leakage and that it is technically easier and faster and protects sphincter function of bile duct in terms of postoperative care and does not to disturb bilioenteric integrity. $\mathrm{HJ}$ is rather preferred in replantation where the recipient's bile ducts are not suitable due to sclerosing cholangitis or previous bile duct surgery, and in pediatric grafts and in the presence of a visible incompatibility between donor's and recipient's bile ducts. Especially in living donor liver transplantation, it is believed that $\mathrm{HJ}$ is more advantageous in terms of long-term complications under the influence of revascularization in $\mathrm{HJ}$ line and the use of large transjejunal stent (28).

Bile complications are divided into two: bile leakage and bile stricture. The treatment approach in both cases varies depending on complication timing, severity and clinical findings. While higher stricture (31.7\%) and lower leakage (16.3\%) are reported as a result of CC in living donor liver transplantation series, higher leakage $(18.2 \%)$ and lower stricture $(7.3 \%)$ are reported as a result of $\mathrm{HJ}$ (40). Ischemic cholangiopathy, Oddi sphincter dysfunction in CC patients and ascending cholangitis in $\mathrm{HJ}$ patients must be assessed as much as technical reasons associated with anastomoses as a part of bile complication assessment. Hepatic artery flow must be definitely checked in bile duct complications due to bile duct sensitivity towards arterial blood build-up.

The objective in treatment is to intervene as early as possible and prevent patient loss due to septic complications and secondary 
biliary cirrhosis $(27,40)$. Retransplantation must be conducted in patients who develop secondary biliary cirrhosis due to refractory bile complication.

Bile leakage usually occurs during early postoperative period and could be from several places such as cross section, anastomosis line, caudate lobe branches or main bile duct of the recipient. Bile leakage from cross section can be treated with percutaneous drainage without requiring reoperation. Anastomosis leakages can be resolved through drainage monitoring, endoscopic stenting or a simple reoperation and primary repair, or otherwise the graft might present a complex picture associated with the ischemia in bile duct. Surgical revision and reanastomosis might be required for anastomosis leakage accompanied by sepsis despite sufficient bile drainage. Even if bile leakage is minor in CC, it creates risk in the long run in terms of bile stricture. Therefore, it might be preferred to dismantle anastomosis and convert it to HJ. Leakages following HJ usually stops spontaneously when anastomosis loge is drained well, and the anastomosis line is closed with fibrosis. However, sepsis risk is higher in these leakages due to intestinal flora presence.

Contrary to bile leakage, bile stricture is usually recognized by disruption in liver functions, cholangitis and dilatation in intrahepatic bile ducts in radiological examination. Anastomotic strictures associated with technical reasons, vascular problems and fibrosis might arise, as well as non-anastomotic strictures particularly associated with ischemic cholangiopathy. Both ERCP and PTC might be used to treat the stricture depending on its location and length, relation with anastomosis, its being single or multiple, and being short or long segment. Particularly focal strictures might be treated with repeated balloon dilation or stents. Yet, retransplantation is especially required in case of diffuse non-anastomotic strictures accompanied by biloma and intrahepatic abscesses

\section{Outcomes of Liver Transplantation}

Liver transplantation provides both a long survival and a very good life quality beyond being a life-saving treatment method in endstage liver disease (41). The outcomes of patients who received liver transplantation are monitored in a multicentric fashion in large databases with broad participation both in the USA (UNOS: United Network for Organ Sharing) and Europe (ELTR: European Liver Transplant Registry). Thanks to the analysis of these databases, it is possible to retrieve centerspecific and cumulative outcomes of cadaveric and living donor liver transplantation. The outcomes of liver transplantation with regard to patient survival as well as graft survival is in constant progress. According to UNOS data, 1, 5 and 10 years of survival rates following liver transplantation are $87.1 \%, 73.3 \%$ and $59.5 \%$ in cadaveric liver transplantation and $89.9 \%$, $77.3 \%$ and $70.8 \%$ in living donor liver trans plantation, respectively (42).

\section{Conclusion}

Transplantation is the simplest, most economic and successful treatment method for patients with end-stage liver failure. Finding sufficient organ from cadaveric transplantation for patients developing end-stage liver disease and acute liver failure is almost impossible. In order to fill the gap, transplantation from living donor has become life-saving. Advanced surgical technique, intense care facilities and postoperative immunosuppressive treatment have facilitated minimizing both donor and patient mortality and morbidity, and transplantation has become widespread as a result of being implemented in more numerous centers.

\section{Declaration of interest}

The authors report no conflict of interest. The authors alone are responsible for the content and writing of the paper.

\section{References}

1. Starzl TE, Groth CG, Brettschneider L, Penn I, Fulginiti VA, Moon JB, et al. Orthotopic homotransplantation of the human liver. Ann Surg. 1968;168(3):392-415.

2. Strong RW, Lynch SV, Ong TH, Matsunami H, Koido Y, Balderson GA. 
Successful liver transplantation from a living donor to her son. N Engl J Med. 1990;322(21):1505-7.

3. Ichida T, Matsunami H, Kawasaki S, Makuuchi M, Harada T, Itoh S, et al. Living related donor liver transplantation from adult to adult for primary biliary cirrhosis. Ann Intern Med. 1995;122(4):275-6.

4. Lo CM, Fan ST, Liu CL, Wei WI, Lo RJ, Lai CL, et al. Adult-to-adult living donor liver transplantation using extended right lobe grafts. Ann Surg. 1997;226(3):261-9; discussion 269-70.

5. de Villa VH, Lo CM, Chen CL. Ethics and rationale of living-donor liver transplantation in Asia. Transplantation. 2003;75(3 Suppl):S2-5.

6. Wachs ME, Bak TE, Karrer FM, Everson GT, Shrestha R, Trouillot TE, et al. Adult living donor liver transplantation using a right hepatic lobe. Transplantation. 1998;66(10):1313-6.

7. Murray KF, Carithers RL Jr; AASLD. AASLD practice guidelines: Evaluation of the patient for liver transplantation. Hepatology. 2005;41(6):1407-32.

8. Pugh RN, Murray-Lyon IM, Dawson JL, Pietroni MC, Williams R Transection of the oesophagus for bleeding oesophageal varices. $\mathrm{Br} \mathrm{J}$ Surg. 1973;60(8):646-9.

9. Oellerich M, Burdelski M, Lautz HU, Binder L, Pichlmayr R. Predictors of one-year pretransplant survival in patients with cirrhosis. Hepatology. 1991;14(6):1029-34.

10. Lucey MR, Brown KA, Everson GT, Fung JJ, Gish R, Keeffe EB, et al Minimal criteria for placement of adults on the liver transplant waiting list: a report of a national conference organized by the American Society of Transplant Physicians and the American Association for the Study of Liver Diseases. Liver Transpl Surg. 1997;3(6):628-37.

11. Malinchoc M, Kamath PS, Gordon FD, Peine CJ, Rank J, ter Borg PC. A model to predict poor survival in patients undergoing transjugular intrahepatic portosystemic shunts. Hepatology. 2000;31(4):864-71.

12. Wiesner R, Edwards E, Freeman R, Harper A, Kim R, Kamath P, et al. Model for end-stage liver disease (MELD) and allocation of donor livers. Gastroenterology. 2003;124(1):91-6.

13. Mazzaferro V, Regalia E, Doci R, Andreola S, Pulvirenti A, Bozzetti F, et al. Liver transplantation for the treatment of small hepatocellular carcinomas in patients with cirrhosis. N Engl J Med. 1996;334(11):693-9.

14. Onaca N, Davis GL, Jennings LW, Goldstein RM, Klintmalm GB. Improved results of transplantation for hepatocellular carcinoma: a report from the International Registry of Hepatic Tumors in Liver Transplantation. Liver Transpl. 2009;15(6):574-80. doi: 10.1002/lt.21738.

15. Berg CL, Gillespie BW, Merion RM, Brown RS Jr, Abecassis MM Trotter JF, et al. Improvement in survival associated with adult-to-adult living donor liver transplantation. Gastroenterology. 2007;133(6): 1806-13. Epub 2007 Sep 14.

16. Northup PG, Abecassis MM, Englesbe MJ, Emond JC, Lee VD, Stukenborg GJ, et al. Addition of adult-to-adult living donation to liver transplant programs improves survival but at an increased cost. Liver Transpl. 2009;15(2):148-62. doi: 10.1002/lt.21671.

17. Patel S, Orloff M, Tsoulfas G, Kashyap R, Jain A, Bozorgzadeh A, et al. Living-donor liver transplantation in the United States: identifying donors at risk for perioperative complications. Am J Transplant. 2007;7(10):2344-9.

18. Middleton PF, Duffield M, Lynch SV, Padbury RT, House T, Stanton P, et al. Living donor liver transplantation--adult donor outcomes: a systematic review. Liver Transpl. 2006;12(1):24-30.

19. Shah SA, Cattral MS, McGilvray ID, Adcock LD, Gallagher G, Smith R et al. Selective use of older adults in right lobe living donor liver transplantation. Am J Transplant. 2007;7(1):142-50.

20. Tucker ON, Heaton N. The 'small for size' liver syndrome.. Curr Opin Crit Care. 2005;11(2):150-5.

21. Mulligan D. Living donor liver transplantation and donor graft size: how small can we go to reduce risk to the donor and what is the cost to the recipient? Liver Transpl. 2009;15(11):1392-4.

22. Chan SC, Fan ST, Lo CM, Liu CL, Wong J. Toward current standards of donor right hepatectomy for adult-to-adult live donor liver transplantation through the experience of 200 cases. Ann Surg. 2007;
245(1):110-7.

23. Taner CB, Dayangac M, Akin B, Balci D, Uraz S, Duran C, et al. Donor safety and remnant liver volume in living donor liver transplantation. Liver Transpl. 2008:14(8):1174-9. doi: 10.1002/tt.21562.

24. Fan ST, De Villa VH, Kiuchi T, Lee SG, Makuuchi M. Right anterior sector drainage in right-lobe live-donor liver transplantation. Transplantation. 2003;75(3 Suppl):S25-7.

25. Lee S, Park K, Hwang S, Kim K, Ahn C, Moon D, et al. Anterior segment congestion of a right liver lobe graft in living-donor liver transplantation and strategy to prevent congestion. J Hepatobiliary Pancreat Surg. 2003;10(1):16-25

26. Lee SG, Hwang S, Kim KH, Ahn CS, Park KM, Lee YJ, et al. Approach to anatomic variations of the graft portal vein in right lobe living-donor liver transplantation. Transplantation. 2003; 75(3 Suppl): S28-32.

27. Kasahara M, Egawa H, Takada Y, Oike F, Sakamoto S, Kiuchi T, et al. Biliary reconstruction in right lobe living-donor liver transplantation: Comparison of different techniques in 321 recipients. Ann Surg. 2006; 243(4):559-66.

28. Hwang S, Lee SG, Sung KB, Park KM, Kim KH, Ahn CS, et al. Longterm incidence, risk factors, and management of biliary complications after adult living donor liver transplantation. Liver Transpl. 2006;12(5): 831-8.

29. Mun HS, Kim KW, Song GW, Ahn CS, Kim SY, Hwang S, et al. Evaluation of the hepatic artery anastomosis by intraoperative sonography with high-frequency transducer in right-lobe graft living donor liver transplantation. J Clin Ultrasound. 2010;38(1):10-6. doi: $10.1002 /$ jcu.20628.

30. Makuuchi M, Sugawara Y. Living-donor liver transplantation using the left liver, with special reference to vein reconstruction. Transplantation. 2003;75(3 Suppl):S23-4.

31. Banff schema for grading liver allograft rejection: an international consensus document. Hepatology. 1997;25(3):658-63.

32. Marudanayagam R, Shanmugam V, Sandhu B, Gunson BK, Mirza DF, Mayer D, et al. Liver retransplantation in adults: a single-centre, 25year experience. HPB (Oxford). 2010;12(3):217-24. doi: 10.1111/ j.1477-2574.2010.00162.x.

33. Romero FA1, Razonable RR. Infections in liver transplant recipients. World J Hepatol. 2011;3(4):83-92. doi: 10.4254/wih.v3.i4.83.

34. Oh CK, Pelletier SJ, Sawyer RG, Dacus AR, McCullough CS, Pruett TL, et al. Uni- and multi-variate analysis of risk factors for early and late hepatic artery thrombosis after liver transplantation. Transplantation. 2001;71(6):767-72.

35. Singh AK, Nachiappan AC, Verma HA, Uppot RN, Blake MA, Saini S, et al. Postoperative imaging in liver transplantation: what radiologists should know. Radiographics. 2010;30(2):339-51.

36. Pinna AD, Smith CV, Furukawa H, Starzl TE, Fung JJ. Urgent revascularization of liver allografts after early hepatic artery thrombosis. Transplantation. 1996;62(11):1584-7.

37. Warner P, Fusai G, Glantzounis GK, Sabin CA, Rolando N, Patch D, et al. Risk factors associated with early hepatic artery thrombosis after orthotopic liver transplantation - univariable and multivariable analysis. Transpl Int. 2011;24(4):401-8.

38. Pastacaldi S, Teixeira R, Montalto P, Rolles K, Burroughs AK. Hepatic artery thrombosis after orthotopic liver transplantation: a review of nonsurgical causes. Liver Transpl. 2001;7(2):75-81.

39. Duffy JP, Hong JC, Farmer DG, Ghobrial RM, Yersiz H, Hiatt JR, et al. Vascular complications of orthotopic liver transplantation: experience in more than 4,200 patients. J Am Coll Surg. 2009;208(5):896-903; discussion 903-5. doi: 10.1016/j.jamcollsurg.2008.12.032.

40. Gondolesi GE, Varotti G, Florman SS, Muñoz L, Fishbein TM, Emre SH, et al. Biliary complications in 96 consecutive right lobe living donor transplant recipients. Transplantation. 2004;77(12):1842-8.

41. Desai R, Jamieson NV, Gimson AE, Watson CJ, Gibbs P, Bradley JA, et al. Quality of life up to 30 years following liver transplantation. Liver Transpl. 2008;14(10):1473-9. doi: 10.1002/lt.21561.

42. OPTN/SRTR 2008 YıllıkRaporu (http://www.ustransplant.org). 